\title{
MODEL OPTIMASI KAPASITAS INDUSTRI PADA KLASTER INDUSTRI HILIR KELAPA SAWIT DI KAWASAN INDUSTRI SEI MANGKEI
}

\section{OPTIMIZATION MODEL OF INDUSTRIAL CAPACITY IN SEI MANGKEI PALM OIL BASED INDUSTRIAL CLUSTER}

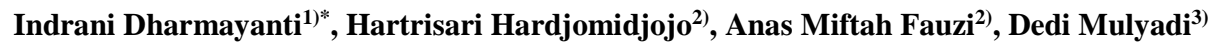 \\ ${ }^{1)}$ Pusdiklat Industri Kementerian Perindustrian \\ J1. Widya Chandra VIII No. 34 Kebayoran Baru, Jakarta Selatan, Indonesia, 12190 \\ Email: iindh522@gmail.com \\ ${ }^{2)}$ Departemen Teknologi Industri Pertanian Institut Pertanian Bogor \\ $\left.{ }^{3}\right)$ Kementerian Perindustrian, Jakarta, Indonesia \\ Makalah: Diterima 23 Juli 2015; Diperbaiki 3 Agustus 2017; Disetujui 2 September 2017
}

\begin{abstract}
Palm oil industrial cluster development in Sei Mangkei is a step to realize the downstream programme, increase the added value and competitiveness through integrated management. To optimize the development, it is necessary to make the planning starting from the selection of potential industries, as well as calculate how optimal capacity, with the availability of raw materials as constraints. The selection of products is done with the exponential comparison method with the result that industrial cooking oil, margarine, basic oleo chemicals, surfactants, biodiesel, industrial soap, liquid soap, shampoo and detergents, as well as biogas and animal feed were potential for development in the industrial park. The goal programming analysis was performed to determine the optimal industrial capacity that provide maximum benefit and labour, and minimal waste produces. Based on the optimization analysis, the profits target was achieved and the largest profits derived from basic oleochemical industry, margarine, cooking oil, and soap bars. While labour targets were not achieved, because labour absorption less than $80 \%$ of the target. The target of waste was achieved, and the largest proportion of liquid waste was produced by cooking oil and basic oleochemicals industry. This model is expected to illustrate the capacity calculation model of industry in other cluster development.
\end{abstract}

Keywords: goal programming, industrial park, optimization, palm oil industrial cluster,

\section{ABSTRAK}

Pengembangan klaster industri kelapa sawit di Sei Mangkei merupakan suatu langkah untuk mewujudkan program hilirisasi, peningkatan nilai tambah dan daya saing melalui pengelolaan industri secara terintegrasi. Agar pengembangan klaster dapat optimal, maka perlu dilakukan perencanaan mulai dari pemilihan industri potensial yang akan dikembangkan, serta menghitung berapa kapasitas optimalnya, dengan mempertimbangkan ketersediaan bahan baku sebagai kendala. Pemilihan produk dilakukan dengan metode perbandingan eksponensial (MPE) dengan hasil bahwa industri minyak goreng, margarin, oleo kimia dasar, surfaktan, biodiesel, industri sabun batang, sabun cair, shampo dan detergen, serta biogas dan industri pakan ternak potensial dikembangkan di Kawasan tersebut. Penentuan kapasitas produksi menggunakan analisis goal programming dengan fungsi tujuan untuk memaksimalkan keuntungan dan serapan tenaga kerja, serta menghasilkan limbah yang minimal. Berdasarkan analisis optimasi, target keuntungan klaster tercapai dan terbesar diperoleh dari industri oleokimia dasar, margarin minyak goreng, serta sabun batang, sedangkan tujuan serapan tenaga kerja tidak tercapai karena yang terserap kurang dari $80 \%$ dari target. Pada aspek limbah target tercapai, dan industri yang terbesar menghasilkan limbah cair adalah industri minyak goreng dan oleokimia dasar. Model ini diharapkan dapat memberi gambaran tentang model penghitungan kapasitas industri dalam pengembangan klaster lainnya.

Kata kunci : goal programming, kawasan industri, optimasi, klaster industri kelapa sawit

\section{PENDAHULUAN}

Kelapa sawit merupakan komoditas yang sangat potensial untuk dikembangkan dalam rangka mendorong perekonomian Indonesia. Sebagai upaya untuk meningkatkan nilai tambah dan daya saing, maka pengelolaan berbagai industri tersebut perlu dilakukan secara terintegrasi mulai dari hulu sampai ke hilir. Konsep klaster industri dapat menjadi salah satu strategi penerapannya sehingga efisiensi industri dapat ditingkatkan dan pada akhirnya diharapkan dapat meningkatkan daya saing industri. Salah satu klaster kelapa sawit yang dikembangkan di Indonesia adalah klaster industri kelapa sawit di kawasan industri Sei Mangkei Sumatera Utara.

Produk-produk turunan kelapa sawit sangat banyak jenisnya. Berbagai pertanyaan muncul dari rencana pengembangan klaster industri kelapa sawit tersebut yaitu produk-produk apa saja yang paling potensial untuk dikembangkan di kawasan tersebut 
dan seberapa besar kapasitas dari masing-masing industri tersebut. Pada saat pengembangan klaster industri tersebut, perlu dipilih jenis industri apa saja yang akan dibangun di kawasan tersebut, agar aliran produk dalam klaster berjalan optimal. Sehingga tahap awal dalam penelitian ini adalah menentukan produk-produk potensial yang akan dibangun.

Salah satu kendala dalam pengembangan klaster industri kelapa sawit adalah ketersediaan bahan baku yang akan menentukan berapa besar kapasitas produksi dari industri-industri yang dibangun. Kapasitas produksi tersebut perlu direncanakan dengan baik agar pengelola kawasan dan stakeholder terkait dapat mempersiapkan berbagai fasilitas, menghitung cost dan benefit dari pembangunan dan merumuskan berbagai perencanaan dan kebijakan turunan lainnya. Dengan adanya kendala ketersediaan bahan baku di atas, tentunya perlu dihitung seberapa besar kapasitas industri optimal yang mungkin dikembangkan. Pada penelitian ini kapasitas industri dihitung dengan mempertimbangkan tiga tujuan yaitu memaksimalkan keuntungan dan serapan tenaga kerja, serta meminimalkan limbah cair yang dihasilkan, dengan kendala ketersediaan bahan baku, aliran material dan keterkaitan produksi antar industri dalam kawasan, serta kapasitas minimal dan maksimal rata-rata industri.

Beberapa penelitian terkait optimasi kapasitas produksi di berbagai perusahaan dilakukan dengan menggunakan metode optimasi goal programming, seperti Elfina (2010); Megasari (2010); Fahrurrozi (2012); Ajiningtyas et al. (2013); Astuti et al. (2013); Fauziyah (2016); dan Nafisah et al. (2016. Pada penelitian ini metode yang sama digunakan untuk menghitung kapasitas produksi dari industri-industri yang akan dibangun dalam klaster industri kelapa sawit di kawasan indusrti Sei Mangkei.

Berdasar latar belakang di atas, tujuan penelitian ini adalah untuk menentukan industri potensial serta kapasitas yang optimal dari masingmasing industri tersebut. Fokus penelitian adalah pada penyusunan model optimasi penentuan kapasitas dari industri turunan kelapa sawit yang akan dibangun di kawasan industri Sei Mangkei, dimana model tersebut dibatasi bahwa klaster yang dikembangkan hanya untuk produk-produk turunan CPO (Crude Palm Oil) dan CPKO (Crude Palm Kernel Oil) dan bahan baku (CPO dan CPKO) dari luar kawasan yang digunakan diasumsikan hanya berasal dari pabrik kelapa sawit (PKS) milik BUMN (PTPN II, III dan IV) yang ada di Sumatera Utara.

\section{METODE PENELITIAN}

\section{Kerangka Pemikiran}

Sei Mangkei merupakan salah satu pusat pengembangan klaster industri kelapa sawit di Sumatera. Berdasarkan kondisi tahap perencanaan pembangunan di kawasan ini, industri-industri potensial yang akan dibangun di kawasan tersebut diseleksi dengan menggunakan Metode Perbandingan Eksponensial (MPE) dimana pakar diminta melakukan penilaian dari sekian produk turunan berdasar kriteria yang telah ditentukan. Selanjutnya berdasarkan potensi bahan baku yang ada, dihitung potensi kapasitas optimal dari industriindustri tersebut dengan menggunakan metode optimasi goal programming dengan tiga goal yang ingin dicapai yaitu memaksimalkan keuntungan, memaksimalkan serapan tenaga kerja dan meminimalkan limbah cair yang dihasilkan. Pengolahan data dan pemodelan matematik dilakukan dengan menggunakan software LINGO.

Metode ini banyak digunakan para peneliti dalam melakukan optimasi pada berbagai bidang. Beberapa peneliti sebelumnya yang menggunakan metode ini adalah Wang dan Liang (2005) yang menggunakan goal programming dalam perencanaan produksi, Bakhtiar (2006) menggunakan metode ini untuk menghitung optimasi sistem angkutan, Listyarini (2008) dalam menganalisis pemborosan listrik di DKI Jakarta, Kruger (2011) yang menggunakan goal programming sebagai pendekatan untuk strategi pengelolaan neraca bank, Sen dan Nandi (2012) dalam perencanaan perkebunan karet di Tripura, Sen dan Nandi (2012) juga menggunakan metode ini untuk pengelolaan penanaman (intercropping) karet dan teh.

Hasil penelitian ini diharapkan dapat memberikan suatu gambaran bagi industri produk turunan sawit dan industri terkait serta industri pendukungnya tentang prospek lokasi pengembangan usahanya; serta bagi pengelola kawasan dan pemerintah dalam perencanaan fasilitas, tata ruang dan menentukan kebijakan operasional pembangunan kawasan.

\section{Tahapan Penelitian}

Tahapan penelitian dimulai dengan melakukan studi literatur untuk mengidentifikasi produk-produk yang dapat dihasilkan dari bahan baku CPO dan CPKO. Selanjutnya adalah penentuan produk yang paling potensial dikembangkan dengan penilaian pakar berdasarkan kriteria yang ditetapkan. Kriteria ini diperoleh dari literatur yang divalidasi oleh pakar. Tahap penentuan ini dilakukan dengan Metode Perbandingan Eksponensial (MPE). Dari hasil ini diperoleh beberapa industri yang potensial dikembangkan dan selanjutnya divalidasi kembali oleh pakar untuk tahap pemilihan dan penentuan jenis industri. Langkah berikutnya adalah melakukan analisis optimasi kapasitas produksi dari industri-industri tersebut dengan menggunakan goal programming. Dalam pemodelan optimasi kapasitas tersebut, perlu diketahui data proses produksi, aliran material dan rantai nilai, keuntungan, serapan tenaga kerja, limbah yang dihasilkan masing-masing industri terpilih, ketersediaan bahan baku, tenaga 
kerja, dan demand masing-masing produk. Dari tahapan ini diperoleh jumlah kapasitas industriindustri yang mungkin untuk dikembangkan dalam klaster. Tahapan penelitian dapat dilihat pada Gambar 1.

\section{Pengumpulan Data}

Data yang dikumpulkan dalam penelitian ini berupa data primer dan sekunder. Data primer diperoleh melalui wawancara langsung dengan para pakar dan melalui pengisian instrumen kuesioner. Pakar yang terlibat berasal dari kalangan peneliti, akademisi, dan praktisi perkelapasawitan. Sedangkan data sekunder diperoleh melalui kajian pustaka, data kelayakan usaha berbagai produk turunan, laporan instansi/dinas terkait, lembaga penelitian, dan BPS. Penelitian dilakukan mulai Juli 2014 sampai dengan Desember 2014. Lokasi penelitian adalah di Kawasan Industri Sei Mangkei, Kabupaten Simalungun, Propinsi Sumatera Utara.

\section{HASIL DAN PEMBAHASAN}

\section{Penentuan Industri Potensial}

Kelapa sawit merupakan salah satu komoditas yang memiliki berbagai produk turunan yang potensial, diantaranya minyak goreng, margarin, minyak makan merah, sorthening, sabun, shampo, detergen, sabun batang, lotion, dan produk kosmetik. Berbagai produk ini tentunya tidak dapat dikembangkan semua di suatu kawasan industri sehingga perlu suatu analisis dalam menentukan produk apa saja yang layak dikembangkan di kawasan tersebut. Alat analisis yang digunakan dalam penelitian ini adalah Metode Perbandingan Eksponensial (MPE). Langkah awal dalam analisis ini adalah dengan menetapkan beberapa kriteria dan bobot yang akan digunakan untuk menseleksi produk-produk turunan.

Kriteria penilaian yang digunakan merupakan kriteria-kriteria yang digunakan beberapa peneliti sebelumnya (Herdhiansyah et al., 2013; Daswilza, 2002, dan Departemen Perindustrian, 2009) yang kemudian divalidasi dengan pertimbangan pendapat pakar (teknik face-validity). Penentuan bobot kriteria pada penelitian ini didasarkan pendapat para pakar yang diolah dengan bantuan software expert choice, dengan hasil disajikan pada Gambar 2.

Berdasarkan pertimbangan pakar, dari sekitar 90 produk turunan kelapa sawit yang terdiri dari produk jadi maupun produk setengah jadi baik pangan dan non pangan (MPOB, 2009 dalam Sipayung, 2012), direduksi menjadi 50 jenis produk, yang selanjutnya akan diseleksi untuk menentukan industri yang paling potensial dikembangkan di Sei Mangkei

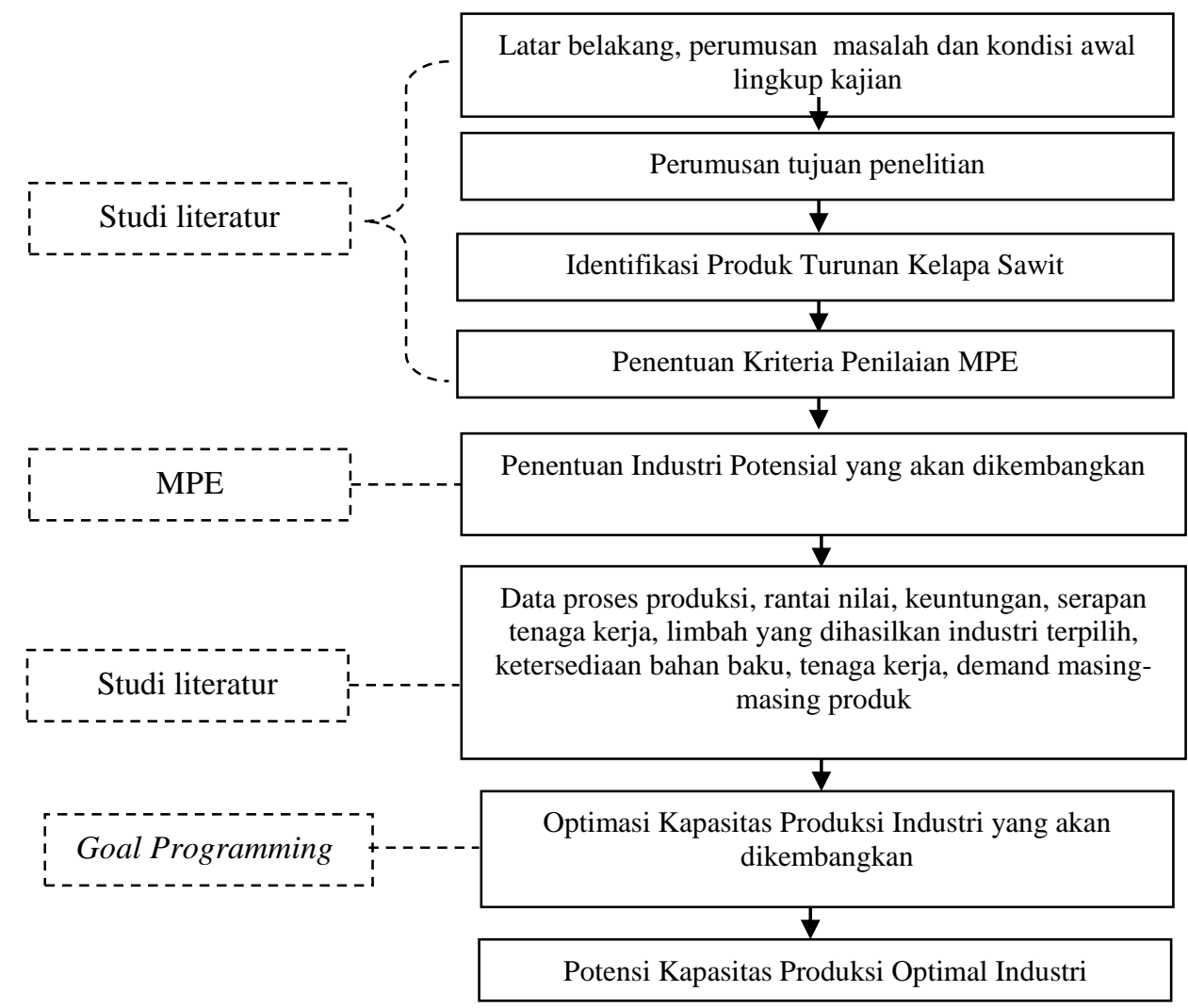

Gambar 1. Tahapan Pemodelan Optimasi 


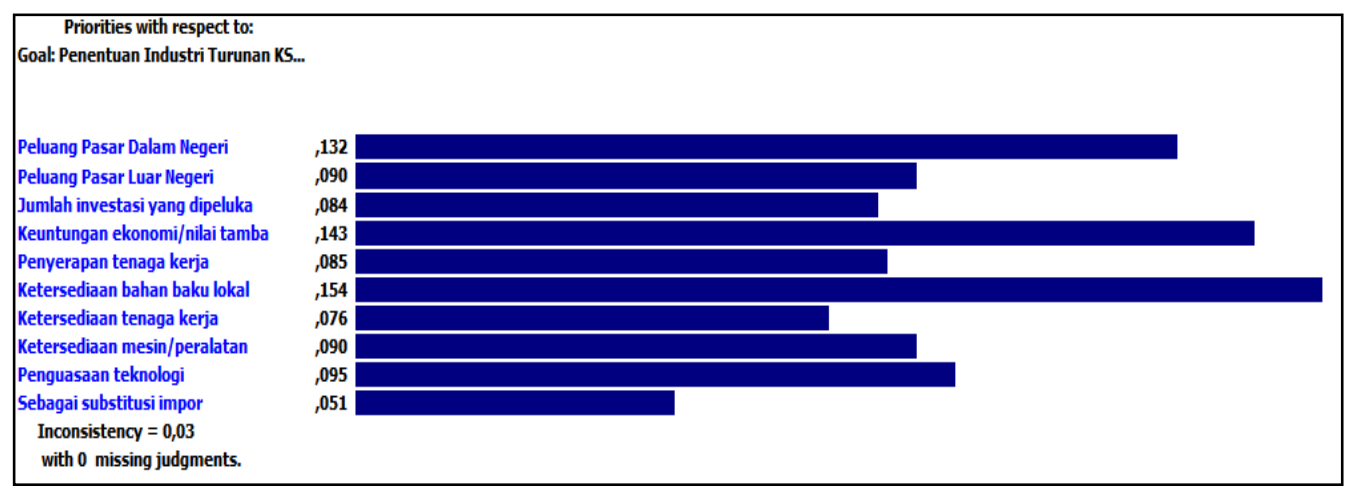

Gambar 2. Bobot kriteria yang digunakan untuk memilih produk potensial

Berdasarkan hasil analisis MPE diperoleh sepuluh kelompok industri produk turunan potensial yaitu :

1. Industri minyak goreng

2. Industri margarin/shortening/vanaspati

3. Industri oleo kimia dasar (Fatty acid, Fatty alcohol, glyserin)

4. Industri surfaktan

5. Industri biodiesel

6. Industri sabun batang

7. Industri shampo, deterjen dan sabun cair

8. Industri deterjen

9. Industri biogas

10. Industri makanan ternak

\section{Optimasi Kapasitas Industri}

Ketersediaan bahan baku kelapa sawit bagi industri turunan yang berada di kawasan industri merupakan salah satu faktor utama yang mendukung berkembangnya klaster industri hilir kelapa sawit. Bagi Kawasan Industri Sei Mangkei potensi bahan baku dapat berasal dari PKS milik PTPN (BUMN) maupun PKS milik swasta. Namun dalam penelitian ini sumber bahan baku dibatasi hanya berasal dari PKS milik PTPN saja. Tabel 1 memperlihatkan data potensi bahan baku CPO dan CPKO untuk kawasan Sei Mangkei.

Penentuan kapasitas optimum industri dalam klaster industri di Kawasan Industri Sei Mangkei dilakukan dengan menggunakan goal programming, dengan tiga goal $(g)$ yang ingin dicapai yaitu :

1. Memaksimalkan keuntungan ekonomi (goal ke1),

2. Memaksimalkan penyerapan tenaga kerja (goal ke-2), dan

3. Meminimalkan limbah cair yang dihasilkan (goal ke-3).

Beberapa informasi, data, dan asumsi yang digunakan dalam analisis ini adalah:

1. Keuntungan yang diperoleh setidaknya sama dengan perencanaan awal kawasan industri yaitu Rp 2,2 triliun per 1 juta ton CPO yang diolah (Kementerian Perindustrian, 2011).
2. Potensi ketersediaan SDM yang dapat terserap di kawasan Sei Mangkei adalah sejumlah angkatan kerja yang masih mengangur di Provinsi Sumatera Utara yaitu sejumlah 379.982 orang (BPS, 2013). Target tenaga kerja yang dapat diserap adalah angkatan terja yang berpendidikan minimal SLTA, dengan jumlah SDM $41 \%$ serta rata-rata keterserapan tenaga kerja disektor industri pengolahan sekitar 7,79\% (BPS, 2013). Dengan pertimbangan tersebut, maka ditentukan target tenaga kerja yang dapat terserap adalah sejumlah 12.203 orang (Dharmayanti, 2015).

3. Limbah cair yang dihasilkan industri di kawasan, diupayakan tidak melebihi kapasitas maksimal pengolahan limbah kawasan. Pada aspek ini pencapaian tujuan dibatasi oleh kuantitas limbah yang dapat diolah oleh instalasi (IPAL) di kawasan yaitu maksimal 0,8 L/detik/ha lahan kawasan yang terpakai (Kementerian Perindustrian, 2010). Dengan target luas areal kawasan yang akan dibangun sampai akhir proyek adalah sekitar $1100 \mathrm{Ha}$ (Kementerian Perindustrian, 2010) dan tingkat efisiensi rata-rata industri sebesar 90\%, maka kapasitas IPAL Kawasan Sei Mangkei adalah sekitar 25 juta $\mathrm{m}^{3} /$ tahun (Dharmayanti, 2015).

4. Penggunaan bahan baku sangat ditentukan oleh proses produksi masing-masing produk turunan. Beberapa produk turunan berbahan baku CPO, RBD (Refined Bleached Deodorized) stearin, dan PKO yaitu minyak goreng, margarin, oleokimia dasar dan biodiesel. Selain itu, ada juga produk yang berbahan baku hasil produksi dari industri turunan lainnya seperti surfaktan, industri sabun, shampo, dan detergen. Sementara untuk industri biogas dan pakan ternak, bahan bakunya merupakan produk samping/limbah dari kebun, PKS, dan industri turunan sawit lainnya.

5. Pada penyusunan persamaan matematik dalam model penentuan kapasitas produksi industri, perlu juga mempertimbangkan proses transformasi bahan baku serta nilai rendemennya. Hal ini diperlukan untuk menghitung kebutuhan bahan baku, keterkaitan rantai nilai dan alokasi optimal bahan baku. 
Tabel 1. Data potensi sumber bahan baku untuk Kawasan Industri Sei Mangkei

\begin{tabular}{clcrr}
\hline No. & Sumber Bahan Baku & $\begin{array}{c}\text { Kapasitas Olah TBS } \\
\text { (Ton / Tahun) }\end{array}$ & $\begin{array}{c}\text { Potensi CPO } \\
\text { (Ton/Tahun) }\end{array}$ & $\begin{array}{c}\text { Potensi CPKO } \\
\text { (Ton/Tahun) }\end{array}$ \\
\hline 1. & PKS PTPN III & 2.700 .000 & 652.860 & 126.900 \\
2. & PKS PTPN II & 1.260 .000 & 388.200 & 75.100 \\
3. & PKS PTPN IV & 4.728 .000 & 1.148 .144 & 222.200 \\
\hline \multicolumn{2}{r}{ Jumlah BB } & & 2.189 .204 & 424.200 \\
\hline
\end{tabular}

Sumber: Dinas Perindustrian dan Perdagangan Propinsi Sumatera Utara (2013) dan PTPN II (2014), PTPN III (2013) dan PTPN IV (2014)

6. Ketersediaan POME (Palm oil Mill Effluent) yang merupakan bahan untuk biogas hanya bersumber dari PKS di kawasan industri yang mengolah 75 ton TBS/jam. Jumlah POME yang dihasilkan dari proses pengolahan TBS adalah sekitar 0,6 ton/ton TBS yang diolah (Fricke, 2009), sehingga potensi POME adalah sekitar 0,27 juta ton/tahun (Dharmayanti, 2015).

7. Ketersediaan pelepah untuk proses produksi pakan ternak ditetapkan tidak terbatas.

Ketersediaan bungkil dihitung sebesar 2\% dari jumlah TBS yang diolah pada Tabel 1 (Fricke, 2009), sehingga potensinya adalah sebanyak 173.760 ton/tahun. Secara umum fungsi tujuan dalam goal programming adalah meminimalkan deviasi di setiap goal. Adapun persamaan umum untuk fungsi tujuannya (Orumie dan Ebong, 2014):

$$
\operatorname{Min} Z=\sum_{g}^{m} w_{g}\left(d_{g}^{-}+d_{g}^{+}\right)
$$

Dimana :

$$
\begin{aligned}
\mathrm{Z}= & \text { fungsi tujuan yang ingin dicapai } \\
\mathrm{w}= & \text { bobot untuk masing-masing sasaran } \\
& \text { (goal) } \\
\mathrm{g}= & \text { sejumlah sasaran (goal) yang ingin } \\
& \text { dicapai }(\mathrm{g}=1,2, \ldots, \mathrm{m}) \\
\mathrm{d}_{\mathrm{g}}^{-}, \mathrm{d}_{\mathrm{g}}^{+}= & \text {deviasi yang di bawah target sasaran pada } \\
& \text { pencapaian goal ke-g } \\
\mathrm{d}_{\mathrm{g}}^{-}, \mathrm{d}_{\mathrm{g}}^{+}= & \text {deviasi yang di atas target sasaran pada } \\
& \text { pencapaian goal ke-g }
\end{aligned}
$$

Analisis optimasi kapasitas industri pada klaster industri Sei Mangkei mempunyai tiga goals $(g)$, sehingga persamaan tujuannya adalah

$$
\operatorname{Min} Z=w_{1} d_{1}^{-}+w_{2} d_{2}^{-}+w_{3} d_{3}^{+}
$$

Dimana ketiga tujuan adalah pertama untuk memaksimalkan keuntungan ekonomi (goal ke-1) dengan meminimalkan deviasi yang kurang dari target $\left(\mathrm{d}_{1}^{-}\right)$dan kedua memaksimalkan penyerapan tenaga kerja (goal ke-2) dengan cara meminimalkan deviasi yang kurang dari target $\left(\mathrm{d}_{2}{ }^{-}\right)$; serta tujuan ketiga adalah meminimalkan limbah cair yang dihasilkan (goal ke-3) dengan cara meminimalkan deviasi yang melebihi target $\left(\mathrm{d}_{3}{ }^{+}\right)$.

Berdasarkan pertimbangan pakar terhadap ketiga goals tersebut maka diperoleh bobot untuk goal ke-1 = 0,540; bobot goal ke-2 =0,297; dan bobot goal ke-3 $=0,163$. Sehingga persamaan tujuan di atas menjadi:

$$
\operatorname{Min} Z=0,540 d_{1}^{-}+0,297 d_{2}^{-}+0,163 d_{3}^{+}
$$

Adapun fungsi kandala dalam penentuan kapasitas ini adalah :

1. Kendala sasaran (goal constrains) :

$$
\sum_{i}^{n} a_{i} \cdot x_{i}+d_{g}^{-}-d_{g}^{+}=G_{g}
$$

a. Goal 1: memaksimalkan keuntungan

$$
T P \geq 2,2 \mathrm{R}_{1} \quad ; \sum_{i=1}^{10}\left(P_{i}, x_{i}\right)+d_{1}^{-}-d_{1}^{+}=2,2 \mathrm{R}_{1}
$$

Dimana :

$\mathrm{G}=$ tujuan atau target yang ingin dicapai

$\mathrm{x}_{\mathrm{i}}=$ variabel keputusan (Kapasitas industri ke-i (juta ton/tahun)

$\mathrm{a}=$ koefisien dari fungsi kendala sasaran (goal)

$\mathrm{i}=$ industri $(\mathrm{i}=1,2, \ldots \ldots .10)$

$\mathrm{TP}=$ total profit kawasan yang menjadi target ( $\mathrm{Rp}$ triliun /tahun)

$\mathrm{R}_{1}=$ jumlah bahan baku (resource) $\mathrm{ke}-1=$ CPO (juta ton)

Nilai $\mathrm{P}_{\mathrm{i}}$ adalah keuntungan dari masingmasing industri ( $\mathrm{Rp}$ juta /ton produk) yang diperoleh dari berbagai sumber dan terangkum pada Tabel 3 .

$1,165 \mathrm{x}_{1}+9,271 \mathrm{x}_{2}+2,82 \mathrm{x}_{3}+1,863 \mathrm{x}_{4}+0,869 \mathrm{x}_{5}+$ $1,055 \mathrm{x}_{6}+9,33 \mathrm{x}_{7}+0,636 \mathrm{x}_{8}+1,233 \mathrm{x}_{9}+0,416 \mathrm{x}_{10}$ $+d_{1}^{-}-d_{1}^{+}=2,2 \mathrm{R}_{1}$

b. Goal 2 : memaksimalkan serapan tenaga kerja

$$
T L \geq 12203 \sum_{i=1}^{10}\left(L_{i} \cdot x_{i}\right)+d_{2}^{-}-d_{2}^{+}=12203
$$

TL adalah total tenaga kerja yang ditargetkan dapat diserap kawasan (orang).

Nilai $\mathrm{L}_{\mathrm{i}}$ adalah jumlah tenaga kerja (labour) yang dapat diserap oleh masing-masing industri (orang / juta ton produk) yang diperoleh dari berbagai sumber dan terangkum pada Tabel 3.

$427 \mathrm{x}_{1}+500 \mathrm{x}_{2}+2491 \mathrm{x}_{3}+2500 \mathrm{x}_{4}+500 \mathrm{x}_{5}+3330$ $\mathrm{x}_{6}+1912 \mathrm{x}_{7}+6000 \mathrm{x}_{8}+3308 \mathrm{x}_{9}+2500 \mathrm{x}_{10}+d_{2}^{-}-$ $d_{2}^{+}=12203$ 
c. Goal 3 : meminimalkan limbah yang diolah

$$
T W \leq 26 \sum_{i=1}^{10}\left(W_{i}, x_{i}\right)+d_{3}^{-}-d_{3}^{+}=26
$$

TW adalah total limbah yang dapat diolah oleh IPAL kawasan (juta $\mathrm{m}^{3} /$ tahun).

Nilai $\mathrm{W}_{\mathrm{i}}$ adalah limbah cair yang dihasilkan oleh industri ke-i ( $\mathrm{m}^{3} /$ ton)yang diperoleh dari berbagai sumber dan terangkum pada Tabel 3.

$5 \mathrm{x}_{1}+5 \mathrm{x}_{2}+4 \mathrm{x}_{3}+4 \mathrm{x}_{4}+10 \mathrm{x}_{5}+8 \mathrm{x}_{6}+8 \mathrm{x}_{7}+1 \mathrm{x}_{8}+10 \mathrm{x}_{9}$ $+10 \mathrm{x}_{10}+d_{3}^{-}-d_{3}^{+}=26$.

\section{Kendala riil (resource constrains) :}

$$
\sum_{i}^{n} b_{i j} x_{i j} \leq=\geq \mathbf{c}_{j}
$$

Beberapa kendala (constrain) yang meliputi penggunaan dan ketersediaan bahan baku, keterkaitan rantai nilai dalam proses produksi dan juga produksi minimal dan maksimum untuk memenuhi permintaan, ditetapkan sebagai batasan dalam perhitungan kapasitas optimal. Dimana $\boldsymbol{b}$ adalah koefisien dari fungsi kendala riil; $\boldsymbol{c}$ adalah jumlah sumber daya yang tersedia.

\section{Ketersediaan Bahan Baku}

Penggunaan CPO disimbolkan $\mathrm{TR}_{1}$ dan penggunaan CPKO disimbolkan dengan $\mathrm{TR}_{2}$ dengan asumsi bahan baku sesuai dengan Tabel 1 .

$$
\begin{aligned}
& \mathrm{TR}_{1} \leq \text { Potensi CPO } \\
& \mathrm{TR}_{2} \leq \text { Potensi CPKO }
\end{aligned}
$$

Selain CPO dan CPKO, beberapa industri menggunakan bahan baku yang berasal dari hasil produksi industri lain, yang menunjukkan adanya keterkaitan produksi dalam klaster. Penggunaan bahan baku masing-masing industri tersebut menjadi kendala dalam model yang dirumuskan dengan persamaan:

$$
T R_{k} \leq \sum_{\forall i} R_{i, k} ; \forall_{\boldsymbol{k}}
$$

Dimana $T R_{k}$ adalah total penggunaan bahan baku ke-k dan $\mathrm{R}_{i, k}$ adalah penggunaan bahan bahan baku ke-k dari industri ke-i. Sebagai langkah untuk mengakomodir keterkaitan proses produksi dan penggunaan bahan baku tersebut, maka diidentifikasi jenis bahan baku, output dan alternatif proses produksi seperti Tabel 2, juga disusun himpunan pasangan berurutan antara bahan baku, output hasil produksi, dan jenis industri (produk utama) serta alternatif proses produksi. Pada model digunakan 13 (tiga belas) jenis bahan baku (R); 14 (empat belas) jenis hasil proses produksi (O); 10 (sepuluh) jenis produk utama; dan 4 (empat) alternatif proses untuk produksi industri oleo kimia dasar, surfaktan dan biodiesel.

Tabel 2. Daftar bahan baku, hasil produksi, produk utama dan alternatif proses

\begin{tabular}{llllll}
\hline & Bahan Baku ( R) & & Hasil Proses Produksi $\left(\mathbf{O}_{\mathbf{q}}\right)$ & & Industri/Produk Utama(X) \\
\hline 1 & CPO & 1 & RBD Stearin & 1 & Minyak goreng \\
2 & CPKO & 2 & RBD Olein & 2 & Margarin \\
3 & RBD Stearin & 3 & PFAD & 3 & Oleo kimia dasar \\
4 & PFAD & $\mathbf{4}$ & Fatty Acid & 4 & Surfaktan \\
5 & Fatty Acid & $\mathbf{5}$ & Gliserin & 5 & Biodiesel \\
6 & Methil Ester & 6 & Margarin & 6 & Sabun batang \\
7 & Gliserin & $\mathbf{7}$ & Methil Ester & 7 & Sabun cair/shampo \\
8 & RBD Olein & $\mathbf{8}$ & Fatty Alkohol & 8 & Deterjen \\
9 & Surfaktan & $\mathbf{9}$ & Surfaktan & 9 & Biogas \\
10 & POME & 10 & Sabun batang & 10 & Pakan ternak \\
11 & Pelepah & 11 & Sabun cair/shampoo & & \\
12 & Bungkil inti & 12 & Deterjen & & \\
13 & Fatty Alkohol & 13 & Biogas & &
\end{tabular}

\section{ALTERNATIF PROSES PRODUKSI}

\section{Industri \\ Produk}

3

Oleo kimia dasar

$4 \quad$ Fatty acid

$\begin{array}{rlll} & 5 & \text { Gliserin } \\ & & & \\ & & & \text { Fatty alcohol } \\ & \text { Surfaktan } & 9 & \text { Surfaktan }\end{array}$

5

Biodiesel

$\begin{array}{ll}5 & \text { Gliserin } \\ 7 & \text { Methyl ester }\end{array}$

\begin{tabular}{ll}
\multicolumn{2}{l}{ Alternatif Proses (v) } \\
1 & Berbahan baku CPO \\
2 & Berbahan baku CPKO \\
3 & Berbahan baku PFAD \\
1 & Berbahan baku CPO \\
2 & Berbahan baku CPKO \\
4 & Berbahan baku F.Acid \\
1. & Berbahan Methyl ester \\
2. & Berbahan baku CPO \\
3. & Berbahan baku CPKO \\
4. & Berbahan Fatty Acid \\
1. & Berbahan baku CPO \\
1. & Berbahan baku CPO \\
2. & Berbahan baku PFAD
\end{tabular}


Tabel 3. Data yang digunakan dalam perhitungan kapasitas optimal

\begin{tabular}{|c|c|c|c|c|c|c|c|c|c|c|}
\hline \multirow{2}{*}{ Parameter } & \multicolumn{10}{|c|}{ Industri } \\
\hline & 1 & 2 & 3 & 4 & 5 & 6 & 7 & 8 & 9 & 10 \\
\hline Kap min : (juta ton) & 0,6 & 0,18 & 0,51 & 0,05 & 0,4 & 0,06 & 0,032 & 0,06 & 0,0019 & 0,775 \\
\hline Kap max : (juta ton) & 2 & 0,36 & 1,5 & 0,1 & 0,6 & 0,3 & 0,14 & 0,22 & 0,016 & 0,775 \\
\hline $\mathrm{P}(\mathrm{i})$ : profit (Rp juta/ton) & 1,165 & 9,271 & 2,82 & 1,863 & 0,869 & 1,055 & 9,33 & 0,636 & 1,2330 & 0,416 \\
\hline L(i) : labor (orang/ jt ton) & 427 & 500 & 2.491 & 2.500 & 500 & 3.330 & 1.912 & 6.000 & 3.308 & 2.500 \\
\hline $\mathrm{W}(\mathrm{i})$ : waste (m3/ton) & 5,0 & 5,0 & 4,0 & 4,0 & 10,0 & 8,0 & 8,0 & 1,0 & 10,0 & 10,0 \\
\hline
\end{tabular}

Sumber : Dharmayanti (2015)

Berikut ini adalah daftar Himpunan Pasangan Berurutan yang menunjukkan keterkaitan antara jenis industri, bahan baku, hasil produksi dan alternatif proses produksi.

A : Himpunan pasangan berurutan antara bahan baku dengan hasil proses produksi yang akan digunakan untuk bahan baku industri lain (produk antara);

$$
\begin{aligned}
A= & \{(3,1),(4,3),(5,4),(6,7),(7,5), \\
& (8,2),(9,9)(13,8)\}
\end{aligned}
$$

B : Himpunan pasangan berurutan antara industri dengan hasil proses produksi (produk utama);

$$
\begin{aligned}
\mathrm{B}= & \{(1,2),(2,6),(3,4),(3,5),(3,8),(4,9), \\
& (5,7)(6,10),(7,11),(8,12),(9,13), \\
& (10,14)\}
\end{aligned}
$$

$\mathrm{V}$ : Himpunan pasangan berurutan antara industri, hasil produk utama dan alternatif proses produksi yang dapat dilakukan untuk menghasilkan produk tersebut;

$$
\begin{aligned}
\mathrm{V}= & (3,4,1),(3,4,2),(3,4,3),(3,5,1), \\
& (3,5,2),(3,8,4),(4,9,1),(4,9,2), \\
& (4,9,3),(4,9,4),(5,5,1),(5,7,1), \\
& (5,7,2)\}
\end{aligned}
$$

$\mathrm{R}$ : Himpunan pasangan berurutan antara industri dan bahan baku yang digunakannya;

$\mathrm{R}=\{(1,1),(2,3),(3,1),(3,2),(3,4),(3,5)$, $(4,1),(4,2),(4,5),(4,6),(5,1),(5,4)$, $(6,3),(6,7),(7,8),(7,9),(8,8)(8,9)$, $(8,13),(9,10),(10,10),(10,11)$, $(10,12)\}$

O : Himpunan pasangan berurutan antara industri dan berbagai produk yang dihasilkan proses produksi industri tersebut;

$$
\begin{aligned}
\mathrm{O}= & \{(1,1),(1,2),(1,3),(2,6),(3,4),(3,5), \\
& (3,8),(4,9),(5,5),(5,7),(6,5),(6,10), \\
& (7,11),(8,12),(9,13),(10,14)\}
\end{aligned}
$$

\section{Proses Produksi dan Rendemennya}

Pencapaian tujuan pada analisis goal programming juga dipengaruhi oleh proses produksi dan rendemen dari proses tersebut, secara rinci persamaannya yang akan diinput kedalam software lingo adalah:

Industri 1;

$$
\begin{array}{ll}
0,75 * \mathrm{R}(1,1) & =\mathrm{O}(1,2) \\
0,20 * \mathrm{R}(1,1) & =\mathrm{O}(1,1) \\
0,05 * \mathrm{R}(1,1) & =\mathrm{O}(1,3)
\end{array}
$$

Industri 2;

$$
\mathrm{R}(2,3)=0,8 * \mathrm{O}(2,6) ;
$$

Industri 3:

$$
\begin{array}{ll}
0,85 * \mathrm{R}(3,1) & =\mathrm{V}(3,4,1) ; \\
0,15 * \mathrm{R}(3,1) & =\mathrm{V}(3,5,1) ; \\
0,85 * \mathrm{R}(3,2) & =\mathrm{V}(3,4,2) ; \\
0,15 * \mathrm{R}(3,2) & =\mathrm{V}(3,5,2) ; \\
0,95 * \mathrm{R}(3,4) & =\mathrm{V}(3,4,3) ; \\
\mathrm{R}(3,5) & =0,99 * \mathrm{~V}(3,8,4) ;
\end{array}
$$

Industri 4;

$$
\begin{array}{ll}
0,969 * \mathrm{R}(4,6)=0,57 * \mathrm{~V}(4,9,1) ; \\
0,82 * \mathrm{R}(4,1) & =0,5 * \mathrm{~V}(4,9,2) ; \\
0,82 * \mathrm{R}(4,2) & =0,5 * \mathrm{~V}(4,9,3) ; \\
0,96 * \mathrm{R}(4,5) & =0,5 * \mathrm{~V}(4,9,4) ;
\end{array}
$$

Industri 5;

$$
\begin{array}{ll}
0,86 * \mathrm{R}(5,1) & =0,87 * \mathrm{~V}(5,7,1) ; \\
0,09 * \mathrm{R}(5,1) & =0,87 * \mathrm{~V}(5,5,1) ; \\
0,95 * \mathrm{R}(5,4) & =0,87 * \mathrm{~V}(5,7,2) ;
\end{array}
$$

\section{Kapasitas Produksi Minimum}

Model juga dibatasi dengan minimum ratarata produksi dari industri yang dianggap layak dikembangkan. Data ini diambil dari berbagai studi kelayakan pembangunan industri turunan sawit yang digunakan sebagai referensi pada penelitian ini.

$$
X(i) \geq \text { Kap min }
$$

\section{Kapasitas Produksi Maksimum}

Selain kapasitas minimal, model juga dibatasi dengan jumlah maksimum produksi yang mungkin dari industri-industri yang ada di dalam klaster. Penentuan kapasitas maksimal ditentukan dengan asumsi bahwa industri di Sei Mangke dapat berproduksi maksimal sejumlah produksi di Sumatera Utara.

$$
\mathrm{X}(\mathrm{i}) \leq \text { Kap max }
$$

\section{Kapasitas Produksi yang Diharapkan}

Pengembangan klaster dilakukan untuk memenuhi suatu harapan tingkat produksi dengan 
mempertimbangkan permintaan, tingkat produksi nasional dan tingkat produksi Sumatera Utara, nilai ekspor dan impor, dan rata-rata kapasitas industri. Dengan pertimbangan pakar, ditentukan kapasitas minimal yang diproduksi di Sei Mangkei sebagai berikut:

$\mathrm{X}_{1} \geq 0,600 ; \mathrm{X}_{2} \geq 0,180 ; \mathrm{X}_{3} \geq 0,510 ; \mathrm{X}_{4} \geq$ 0,$05 ; \quad X_{5} \geq 0,400 ; \quad X_{6} \geq 0,060 ; \quad X_{7} \geq$ 0,$032 ; X_{8} \geq 0,060 ; X_{9} \geq 0,002$ dan $X_{10} \geq$ 0,775 .

$\mathrm{Xi}$ adalah produk utama dari industri $\left(\mathrm{O}_{i, q}\right)$ yang dikembangkan dengan mengikuti persamaan kapasitas industri sebagai berikut:

$$
X_{i}=\sum_{q} O_{i, q} \quad(\mathrm{i}, \mathrm{q}) \in \mathrm{B}
$$

Ketersediaan bahan baku (produk antara) yang akan digunakan untuk produk lanjutan dalam kawasan, sangat dipengaruhi oleh output yang dihasilkan dari proses produksi $\left(\mathrm{O}_{i, q}\right)$ dan produk antara yang dijual keluar kawasan $\left(\mathrm{Y}_{\mathrm{q}}\right)$. Persamaan ketersediaan produk antara adalah sebagai berikut:

$$
T R_{k}=\sum_{\forall i} O_{i, q}-Y_{q} ;(\mathrm{k}, \mathrm{q}) \in \mathrm{A}
$$

Beberapa produk ke-q tidak digunakan lagi sebagai bahan baku industri lainnya, dan akan langsung dijual keluar kawasan. Hal ini diformulasikan dengan:

$$
Y_{q}=O_{i, q} ;(\mathrm{i}, \mathrm{q}) \in \mathrm{B} ; \quad(\mathrm{q}=6,10,11,12,13,14)
$$

Pada beberapa industri, output $(\mathrm{O})$ dapat dihasilkan dari beberapa alternatif proses produksi dan bahan baku (multi proses), hal ini diformulasikan dengan:

$$
O_{i, q}=\sum_{n} U_{i, q, n} \quad(\mathrm{i}, \mathrm{q}, \mathrm{n}) \in \mathrm{V}
$$

3. Kendala Non Negativitas :

$$
x_{i j}, d_{i}^{-}, d_{i}^{+} \geq 0, w_{i}>0
$$

Dimana :

$\mathrm{TR}_{\mathrm{k}}=$ total bahan baku ke-k

$\mathrm{R}_{\mathrm{i}, \mathrm{k}}=$ jumlah bahan baku ke-k yang digunakan oleh industri ke-i

$\mathrm{R}_{1}=$ jumlah CPO (bahan baku 1) yang diolah

$\mathrm{Y}_{\mathrm{q}}=$ produk utama ke-q yang akan dijual keluar kawasan (juta ton)

$\mathrm{O}_{\mathrm{i}, \mathrm{q}}=$ ouput produk utama ke-q pada industri ke-i (Juta ton)

$\mathrm{U}_{\mathrm{i}, \mathrm{q}, \mathrm{n}}=$ ouput produk utama ke-q, pada industri ke,i pada alternative proses produksi ke-n (Juta ton)

$\mathrm{k} \quad=$ bahan baku $(\mathrm{k}=1,2, \ldots \ldots 13)$

$\mathrm{q}=$ hasil industri/produk utama $(\mathrm{q}=1,2, \ldots \ldots .14)$

$\mathrm{n}=$ alternatif proses produksi $(\mathrm{n}=1,2,3,4)$

Berdasarkan hasil simulasi persamaanpersamaan dan informasi di atas dengan software Lingo, dilakukan analisis dan diperoleh hasil capaian fungsi tujuan seperti pada Tabel 4. Dari hasil

\begin{tabular}{|c|c|c|c|c|c|}
\hline GOAL & Target & Capaian & $\mathrm{d}_{\mathrm{g}}^{-}, \mathrm{d}_{\mathrm{g}}^{+}$ & $\mathrm{d}_{\mathrm{g}}^{-}, \mathrm{d}_{\mathrm{g}}^{+}$ & Status \\
\hline $\begin{array}{l}\text { 1. Maksimalkan keuntungan } \\
\text { (Rp triliun/th) }\left(\min d_{1}^{-}\right)\end{array}$ & 4,816 & 9,399 & 4,583 & - & Satisfied \\
\hline $\begin{array}{l}\text { 2. Maksimalkan serapan tenaga kerja } \\
(\text { orang })\left(\min d_{2}^{-}\right)\end{array}$ & 12.203 & 8.477 & - & 3.726 & Unsatisfied \\
\hline $\begin{array}{l}\text { 3. Minimalkan limbah yang diolah } \\
\left.\text { (juta } \mathrm{m}^{3} / \mathrm{th}\right)\left(\min d_{3}^{+}\right)\end{array}$ & 26 & 20,4 & - & 5,6 & Satisfied \\
\hline
\end{tabular}
analisis di atas juga diperoleh kapasitas optimum untuk industri-industri yang direncanakan dibangun sebagaimana ditunjukkan dalam Tabel 5.

Tabel 4. Hasil simulasi goal programming

Sumber : Hasil analisa dengan software Lingo

Tabel 5. Hasil perhitungan optimasi kapasitas pada klaster industri Sei Mangkei

\begin{tabular}{llccc}
\hline Produk Industri & \multicolumn{3}{c}{ Data (juta ton / tahun) } & Hasil optimasi kapasitas \\
\cline { 2 - 4 } (juta ton / tahun)
\end{tabular}


Berdasar kapasitas optimal pada Tabel 5, kemudian dihitung seberapa besar keuntungan, serapan tenaga kerja serta jumlah limbah cair yang dihasilkan kesepuluh industri tersebut. Dari hasil simulasi terlihat bahwa CPO dan CPKO banyak terserap pada industri oleokimia dasar, karena pada industri tersebut tingkat keuntungannya paling tinggi, berikutnya industri margarin, shampo/sabun mandi cair dan industri minyak goreng.

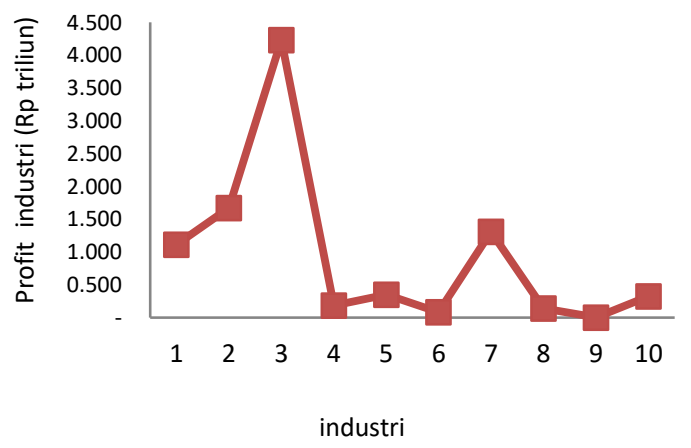

Gambar 3. Keuntungan industri pada klaster industri kelapa sawit

Dari hasil simulasi juga terlihat bahwa target serapan tenaga kerja tidak tercapai, karena hanya sekitar 8.600 orang $(70 \%)$ yang terserap pada indusri dalam klaster. Tenaga kerja yang paling banyak terserap adalah pada industri oleokimia dasar (38\%), lalu industri pakan (19\%) dan deterjen $(13 \%)$.

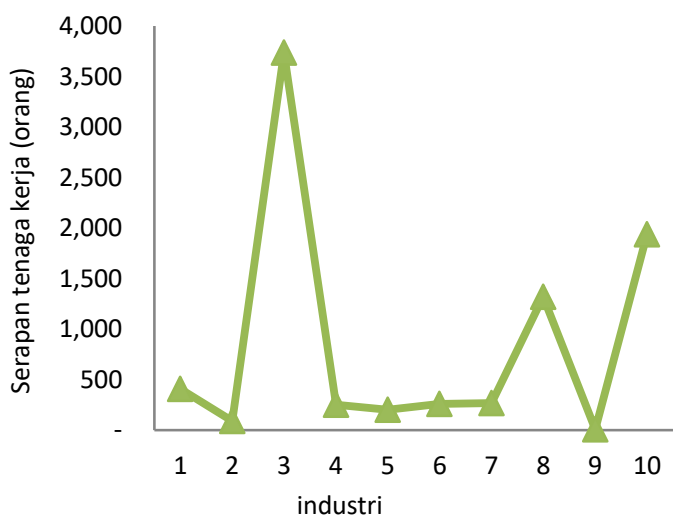

Gambar 4. Jumlah tenaga kerja yang terserap pada klaster industri kelapa sawit Sei Mangkei

Aspek terakhir yang dianalisis adalah limbah. Hasil simulasi menunjukkan bahwa industri yang menghasilkan limbah cair paling banyak adalah oleokimia dasar $(30 \%)$, minyak goreng $(23 \%)$ dan biodiesel (19\%) dari total limbah yang dihasilkan kawasan.

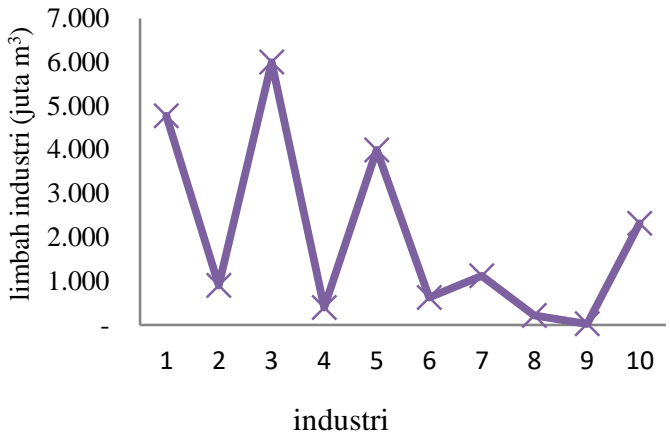

Gambar 5. Limbah cair yang dihasilkan di Kawasan Industri Sei Mangkei

\section{KESIMPULAN DAN SARAN}

\section{Kesimpulan}

Produk turunan kelapa sawit yang potensial dikembangkan di Kawasan Industri Sei Mangkei berikut dengan kapasitas optimalnya (juta ton/tahun) berdasar potensi bahan baku yang ada adalah industri minyak goreng $(0,96)$; industri margarin/shortening/vanaspati $(0,18)$; industri oleo kimia dasar (Fatty acid, Fatty alcohol, glyserin) $(1,5)$; industri surfaktan $(0,1)$; industri biodiesel $(0,4)$; industri sabun batang $(0,08)$; industri sabun cair dan shampho $(0,14)$; industri detergen $(0,22)$; biogas $(0,002)$ dan industri makanan ternak $(0,78)$.

Keuntungan terbesar bagi kawasan diperoleh dari industri oleokimia dasar, industri margarin, shampo/sabun mandi cair dan industri minyak goreng. Tenaga kerja yang paling banyak terserap adalah pada industri oleokimia dasar, lalu industri pakan dan deterjen. Namun dari total tenaga kerja yang terserap tidak memenuhi target yang ditetapkan. Limbah pada kawasan paling banyak dihasilkan oleh industri oleokimia dasar, minyak goreng dan biodiesel.

\section{Saran}

Untuk melengkapi dan meningkatkan akurasi model optimasi kapasitas industri di Kawasan Industri Sei Mangkei beberapa aspek yang perlu dikaji lebih lanjut adalah:

1. Asumsi penggunaan bahan baku tidak hanya terbatas pada CPO dan CPKO yang bersumber dari PKS milik PTPN, namun perlu dipertimbangkan untuk mempertimbangkan bahan baku dari PKS milik swasta.

2. Diharapkan dapat dilakukan kajian-kajian lanjutan dengan mempertimbangkan kendala ketersediaan lahan kawasan dan perencanaan kawasan yang dinamis.

3. Dari hasil penelitian dan penelaahan masterplan kawasan, maka pengembangan kawasan perlu diarahkan kepada komoditi-komoditi yang direkomendasikan ini. Mengingat kawasan meski telah dibuat blok-blok namun secara tegas 
peruntukannya belum ditentukan. Hal ini akan menentukan target promosi dan pemasarann kawasan.

4. Pada level strategis, diperlukan kajian yang bersifat kebijakan yaitu bagaimana rancangan ini dapat diimplementasikan secara nyata oleh seluruh stakeholder dan shareholder yang terlibat dalam pengembangan klaster industri kelapa sawit ini.

\section{DAFTAR PUSTAKA}

Ajiningtyas P, Suhud W, dan Farida A. 2013. Penerapan metode goal programming untuk perencanaan produksi pada produk olahan tebu (Studi Kasus : PT. XXX, Jawa Timur). Jurnal Teknik POMITS. 1 (1) : 1-6.

Astuti N, Linawati L, dan Mahatma T. 2013. Penerapan model linear goal programming untuk optimasi perencanaan produksi. institutional repository Universitas Kristen Satya Wacana. [online] http://repository.uksw.edu/handle/12345678 9/3014. [18 Mei 2014].

Bakhtiar A, Sari DP, dan Tantono H. 2006. Penentuan jumlah bus yang optimal dengan menggunakan metode goal programming. J@TI Undip. 1 (1) : 42-50.

BPS (Badan Pusat Statistik). 2013. Ekspor-Impor. [online] www.bps.go.id. [8 Desember 2014].

BPS (Badan Pusat Statistik). 2013. Sumatera Utara Dalam Angka Tahun 2013.

Daswilza. 2002. Penentuan komoditas unggulan agribisnis dan strategi pengembangannya di Kabupaten Agam, Propinsi Sumatera Barat. [Tesis]. Bogor: Institut Pertanian Bogor

Departemen Perindustrian. 2009. Pengembangan kompetensi inti daerah dalam rangka peningkatan daya saing daerah. Jakarta: Biro Perencanaan. Departemen Perindustrian.

Dharmayanti I. 2015. Desain model pengembangan klaster industri hilir kelapa sawit di kawasan industri Sei Mangkei. [Disertasi]. Bogor : Institut Pertanian Bogor.

Dinas Perindustrian dan Perdagangan Propinsi Sumatera Utara. 2013. Data PKS di Sumatera Utara (data tidak dipublikasikan)

Elfina TRS. 2010. Perencanaan kapasitas produksi menggunakan metode linear goal programming. [Skripsi]. Medan : Universitas Sumatera Utara.

Fahrurrozi. 2012. Optimasi perencanaan produksi dengan metode goal programming di PT. Jakarana Tama. [Skripsi]. Medan : Universitas Sumatera Utara.

Fauziyah. 2016. Penerapan metode goal pragramming untuk mengoptimalkan beberapa tujuan pada perusahaan dengan kendala jam kerja, permintaan dan bahan baku. Jurnal Matematika Mantik. 2 (1): 52-59.

Fricke TB. 2009. Buku Panduan Pabrik Kelapa Sawit Skala Kecil untuk Produksi Bahan Baku Bahan Bakar Nabati (BBN). Jakarta (ID): US AID

Herdhiansyah D, Lilik S, Didik P, Taryono. 2013. Kriteria kualitatif penentuan produk unggulan komoditas perkebunan dengan metode delphi di Kabupaten KolakaSulawesi Tenggara. Agritech. 33(1). Tersedia pada: Http://www.jurnalgritech.tp.ugm.ac.id/ojs/index.php/agritech/ article/ view/266

Kementerian Perindustrian. 2010. Peraturan Menteri Perindustrian Nomor 35/MIND/PER/3/2010 tentang Pedoman Teknis Kawasan Industri.

Kementerian Perindustrian. 2011. Penyusunan Studi Kelayakan Ekonomi dan Finansial Kawasan Ekonomi Khusus Sei Mangkei. Direktorat Jenderal Pengembangan Perwilayahan Industri Kementerian Perindustrian. Jakarta

KPPU [Komisi Pengawas Persaingan Usaha]. 2010. Positioning Paper Minyak Goreng. [internet]

www.kppu.go.id/docs.positioning_paper/po sitioning_paper minyak_goreng.pdf. [10 Mei 2014].

Kruger M. 2011. A Goal Programming Approach to Strategic Bank Balance Sheet Management. SAS Global Forum Paper 024. North-West University. South Africa.

Listyarini S. 2008. Penggunaan Goal Programming Untuk Menganalisis Pemborosan Listrik Di DKI Jakarta. Jurnal Program Studi Pengelolaan Lingkungan Jurusan Biologi FMIPA Universitas Terbuka.

Megasari K. 2010. Goal programming untuk perencanaan produksi agregat dengan kendala sumber daya. [Skripsi]. Surabaya : Institut Teknologi Sepuluh Nopember.

Nafisah L, Sutrisno, dan Yan E. 2016. Perencanaan produksi menggunakan goal pragramming (Studi Kasus di Bakpia Pathuk 75 Yogyakarta). Jurnal Spektrum Industri. 14 (2) : $209-215$

Orumie UC dan Ebong D. 2014. A Glorious literature on linear goal programming algorithms. American Journal of Operations Research. 4 : 59-71.

PTPN II. 2014. Kinerja PTPN II. [internet]. Tersedia pada: http://ptpn2.com/main/index.php/kinerjaper usahaan/oprasional. [ 21 Desember 2014].

PTPN III. 2013. Annual Report PTPN III Tahun 2012. [ Data tidak dipublikasikan] 
PTPN IV. 2014. Kinerja PTPN IV. [internet]. Tersedia pada http://www.ptpn4.co.id/ kinerja/. [14 Desember 2014].

Sen N dan Nandi M. 2012. A Goal programming approach to rubber plantation planning in tripura. Applied Mathematical Sciences. 6 (124) : $6171-6179$.

Sen N dan Nandi M. 2012. A goal programming approach to rubber-tea intercropping management in Tripura. Asian Journal Of Management Research. 3 (1) : 178-183.

Sipayung T. 2012. Ekonomi Agribisnis Minyak Sawit. Bogor : IPB Press.
Trievita AF dan Pamilia C. 2012. Pengaruh perbedaan ukuran partikel dari ampas tebu dan konsentrasi natrium bisulfit $\left(\mathrm{NaHSO}_{3}\right)$ pada proses pembuatan surfaktan. Jurnal Teknik Kimia. 18(4).

Wang RC dan Liang TF. 2005. Aggregate production planning with multiple fuzzy goals. International Journal $A d v$ Manufacturing Technology (2005) 25: 589-597. 